\title{
Assessment of Artisan Clay Bricks for Structural Strength, Chemical Stability and Durability
}

\author{
Nabbala Moses Mumpembe, Muhwezi Lawrence, Kyakula Michael \\ Civil and Building Engineering Department, Faculty of Engineering, Kyambogo University, Kampala, Uganda \\ Email address: \\ nabbalamoses@gmail.com (N. M. Mumpembe), Imuhwezi@hotmail.com (M. Lawrence), mkyakula@gmail.com (K. Michael)
}

\section{To cite this article:}

Nabbala Moses Mumpembe, Muhwezi Lawrence, Kyakula Michael. Assessment of Artisan Clay Bricks for Structural Strength, Chemical Stability and Durability. Journal of Civil, Construction and Environmental Engineering. Vol. 5, No. 6, 2020, pp. 178-190.

doi: $10.11648 /$ j.jccee.20200506.15

Received: November 28, 2020; Accepted: December 17, 2020; Published: December 31, 2020

\begin{abstract}
The artisan clay bricks in Uganda are characterised with low strength, erosion, tiny cracks, lime pop out, warping, efflorescence occurrence and high-water absorption. The raw clay and artisan burnt clay brick samples were collected from artisan brick making places (sites) from Eastern, Central and Northern Uganda. The sampling was done using IS-5454 procedures. Testing was carried out for; water absorption, mineral percentage investigation in natural and purified clay in terms of $\mathrm{SiO}_{2}, \mathrm{Al}_{2} \mathrm{O}_{3}, \mathrm{Fe}_{2} \mathrm{O}_{3} \& \mathrm{CaO}$, compressive strength of the artisan clay unit, improved chemical composition artisan clay units from purified clay and improved molded bricks from raw clay. Results indicated mineral requirements for manufacturing bricks was not satisfactory, for artisan bricks, they had very low characteristic strengths of $0.63 \mathrm{~N} / \mathrm{mm}^{2}$ for Lira and $0.38 \mathrm{~N} / \mathrm{mm}^{2}$ for Mukono. Refining and change on molding process was done and the raw clay structure shifted to the positive side of the required mineralogy. Fired bricks on testing gave higher characteristic strengths of 2.2 (improved chemical composition bricks) and 3.3 (improved molded bricks) for Lira, 5.12 (improved chemical composition bricks) and $2.62 \mathrm{~N} / \mathrm{mm}^{2}$ (improved molded bricks) for Mukono, slight efflorescence and low water absorption. Studies therefore recommend that the artisan do include both refining processing and constant force kneaded clay pressing in the manufacturing process.
\end{abstract}

Keywords: Brick for Structural Strength, Chemical Stability, Durability

\section{Introduction}

\subsection{Background}

Bricks are the commonly used forms of building materials in the construction of buildings in the world and are one of the oldest [1] known building materials dating back to 7000BC. Clay bricks have been widely preferred as building material because of their high compressive strength, durability, fire and weathering resistance, thermal and sound insulation [7]. Basic principles of manufacturing bricks are fairly the same but individual manufacturers do tailor their manufacturing process to fit their particular clay raw materials. Process tailoring to fit particular clay causes brick makers/manufacturers to make mistakes leading to poor quality products which are characterised of Lime pop out, blistering (tiny holes), cracks, warping, softness or low strength under burning, efflorescence, brick erosion, high water absorption etc.

Bricks in first class should not absorb more than one sixth of its dry weight, second class should not absorb more than a quarter of its dry weight [15]. For brick manufacturing, clay must possess some specific properties and characteristics. Clay is one of the most abundant natural materials on earth [5]. Clay do occur in three principal forms i.e., Surface clays, shale's and fire clays of which of these forms have similar chemical compositions [5]. The three forms are composed of silica and alumina with varying amounts of metallic oxides. The type and source of clay used in the manufacturing of bricks varies greatly depending on the geographical locations of the manufacturing site [7]. The manufacturer minimizes variations in chemical compositions and physical properties by mixing clay from different locations in the pit. During mining it is observed that there is a variation of chemical composition even in the same pit. These variations are compensated for by varying manufacturing processes. Clay bricks in Uganda are manufactured by Artisans, small and medium scale manufacturers. Around $84 \%$ of all Ugandan houses have brick walls compared to the $12 \%$ which is built with mud and poles 
[11]. The artisan clay bricks manufacturers' products are estimated to be over $80 \%$ of the brick products in Uganda and are characterized with defects on the market. Artisan clay bricks are relatively cheaper than medium scale manufacturers in Uganda. Clay bricks manufactured by the artisans in Uganda and Tanzania are more than $10 \%$ wasted during transportation, handling and construction process on sites [11].

To address the issue of artisan clay bricks for structural strength, chemical stability and durability in Uganda, this research focused on the study of the right manufacturing process, identification of the physical and chemical properties of raw clay to be used as per geographical location, design of simple methods of refining raw clay to meet specific characteristics properties of producing durable, chemically stable and strong burnt clay brick.

\subsection{Statement of the Problem}

The artisan manufactured bricks in Uganda are largely characterized by defects like lime pop out, warping, cracks, high water absorption, erosion, blistering, low compressive strength, occurrences of efflorescence on built walls which is assign of poor-quality brick. The characterized defects of the artisan manufactured clay brick in Uganda leads to low strength of walling units, dump rooms, poor appearance of walls, frequent repainting of walls, lack of trust for structural specification during design process, high projects cost due to high waste generation during handling and construction, less durability of structures and variations in quality of brick products. The possible causes of poor-quality bricks could be, the poor chemical composition of clay, presence of coarse materials in the clay and poor methods of manufacturing. There is need therefore to improve the quality of bricks by refining raw clay and applying improved manufacturing methods.

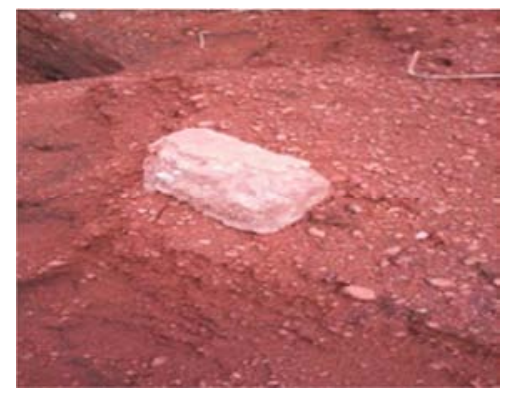

Figure 1. Erosion.

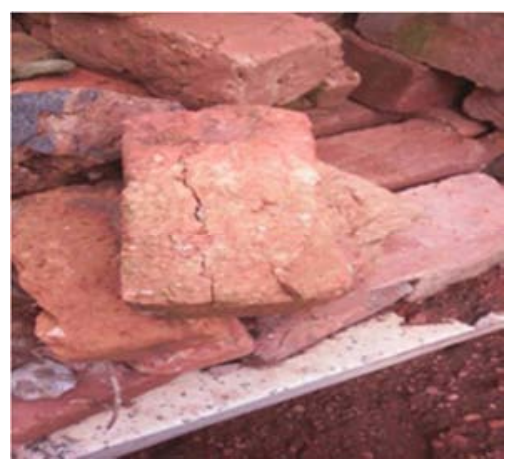

Figure 2. Cracks and breakage.

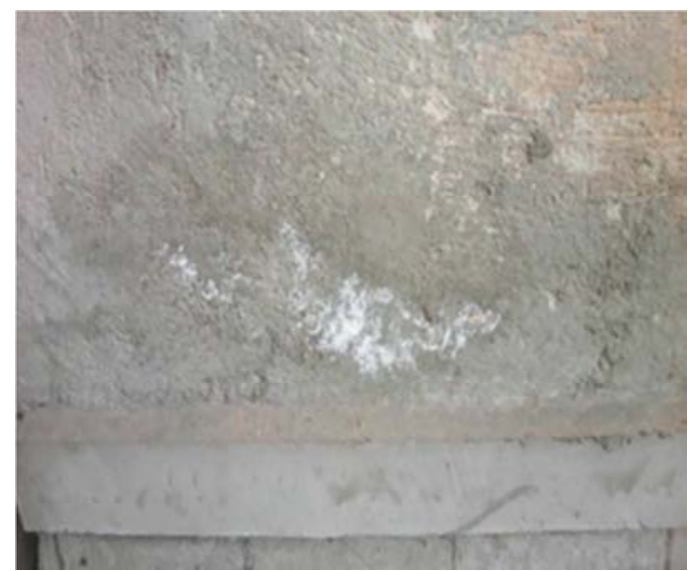

Figure 3. Efflorescence.

\subsection{Objective of the Study}

\subsubsection{Main Objective}

To assess causes of poor structural strength, chemical instability and low durability of artisan manufactured clay bricks in Uganda and recommend measures for improvement.

\subsubsection{Specific Objectives}

The specific objectives of the study are:

1. Establish the present manufacturing process used by the artisans in the manufacture of local clay bricks;

2. To determine the chemical percentage $\left(\mathrm{Al}_{2} \mathrm{O}_{3}, \mathrm{SiO}_{2}\right.$, $\mathrm{Fe}_{2} \mathrm{O}_{3}$ and $\mathrm{CaO}$ ) compositions of clay locally used by the artisans, in manufacturing bricks in Uganda [17, 18];

3. To improve on the percentage chemical $\left(\mathrm{Al}_{2} \mathrm{O}_{3}, \mathrm{SiO}_{2}\right.$, $\mathrm{Fe}_{2} \mathrm{O}_{3}$ and $\mathrm{CaO}$ ) composition ratios as related to the ideal composition for quality;

4. Recommend a new method of manufacturing improved artisan clay brick to meet specific characteristics properties of producing durable, chemically stable and strong burnt clay brick.

\subsection{Research Questions}

The research was aimed at addressing the following research questions:

1. What methods do artisans follow during manufacturing of local clay bricks in Uganda?

2. What are the natural percentage chemical $\left(\mathrm{Al}_{2} \mathrm{O}_{3}, \mathrm{SiO}_{2}\right.$, $\mathrm{Fe}_{2} \mathrm{O}_{3}$ and $\mathrm{CaO}$ ) compositions of artisan brick making clay in specific geographical locations in Uganda?

3. How can the natural composition of the percentage chemical $\left(\mathrm{Al}_{2} \mathrm{O}_{3}, \mathrm{SiO}_{2}, \mathrm{Fe}_{2} \mathrm{O}_{3}\right.$ and $\left.\mathrm{CaO}\right)$ be improved to produce chemically stable, durable and strong artisan brick?

4. What can be done to improve the brick manufacturing process to produce the chemically stable, durable, strong and reliable artisan clay brick for construction?

\subsection{Justification of the Study}

Building projects (that employs artisan local clay bricks), incur high costs during handling, transportation and 
construction because of weak nature of the artisan bricks [11]. This research seeks to mitigate/reduce these costs. Design Consultants need make use of reliable artisan locally manufactured clay brick for design specification. This research seeks to improve manufacturing process for production of reliable artisan clay brick and thus improve structural strength, chemical stability and durability. Dampness due to poor class of bricks that absorption high water in the houses built by the use of low-class artisan brick need to be eliminated. Defects largely characterised with efflorescence turn houses poor looking because of the migrations of the salts, and this research seeks to minimize these effects.

\subsection{Significance of the Study}

The study has provided adequate information to consulting engineers a basis of design specification on the grade of artisan clay brick with improved manufacturing process by Ugandan artisans. The research has provided adequate information regarding the purification of the raw clay to get the appropriate percentage chemical composition leading to chemically stable, durable and structural clay artisan brick that is economical for structural works in Uganda. The introduction of the clay purification formula and improved molding will lead to production of quality artisan clay brick consequently increase time interval for repainting the houses, high compressive crushing strength, smart looking products, add value to knowledge body and hence value engineering.

\subsection{Scope and Limitations of the Study}

\subsubsection{Geographical}

The research was conducted in Uganda. Representative clay samples were obtained from the artisan manufacturing sites in the districts of Mukono, Lira and Kamuli.

\subsubsection{Time}

The research was conducted from December 2018 to October 2020.

\subsubsection{Content Scope}

The research was limited to manufacturing of brick from raw and purified clay, tests for water absorption, compressive crushing strength tests, efflorescence of the improved chemically composition artisan, improved molded brick \& artisan burnt clay brick, percentage chemical analysis of $\left(\mathrm{Al}_{2} \mathrm{O}_{3}, \mathrm{SiO}_{2}, \mathrm{Fe}_{2} \mathrm{O}_{3}\right.$ and $\left.\mathrm{CaO}\right)$ for both raw clay and purified clay.

\subsection{Conceptual Framework}

The strength, chemical stability and durability of clay bricks depends on the chemical composition of clay and on the manufacturing process which includes mixing, proportionating of clay constituents, drying and brick firing [14]. The independent variables which are indicators of variables are the manufacturing processing quality for classifications of bricks are compressive strength, water absorption and efflorescence. The dependant used by the artisan and the chemical structure of the clay used.

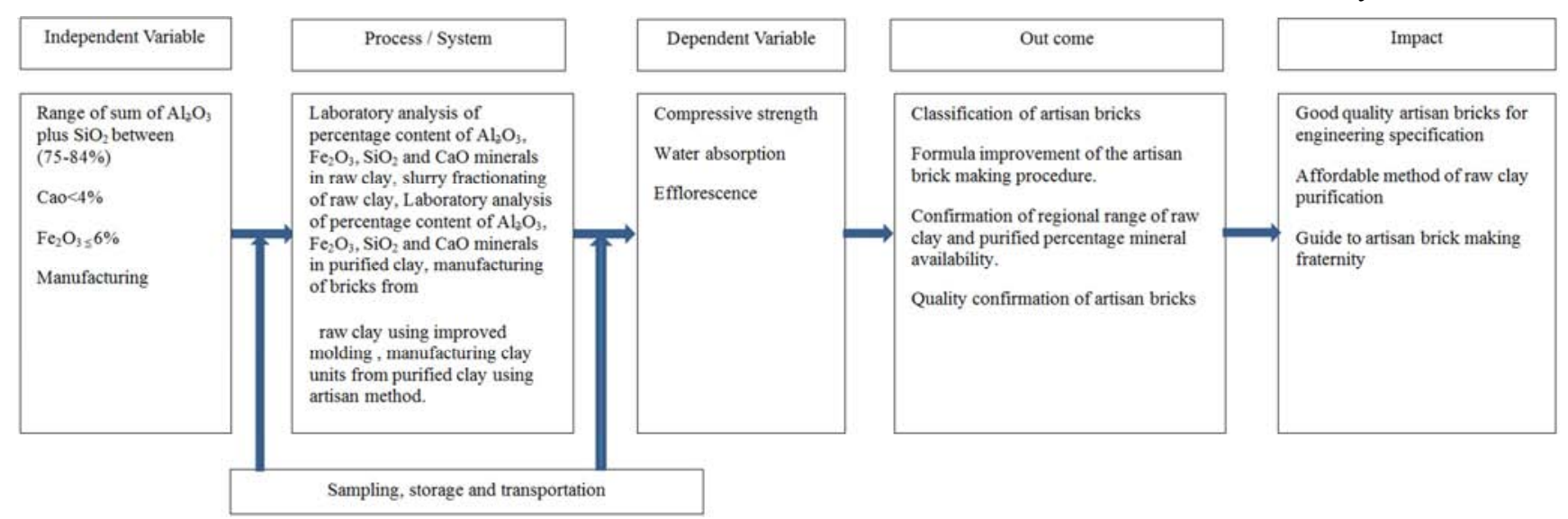

Figure 4. Conceptual frame work.

\section{Methodology}

\subsection{Introduction}

This chapter provides the methodology that was adopted in order to achieve the objectives. It describes the conditions of clay in its natural state, process of purifying the natural clay to yield the level of mineral percentage proportionality required for high quality production of clay brick, process of manufacturing bricks.

It further describes the methods of determining the compressive crushing strengths, water absorption, efflorescence ability and classification of bricks.

\subsubsection{Study Area}

Districts in Uganda were divided into four major regions i.e. northern, eastern, western and central. Random sampling was carried out. Results were that Mukono was picked for central, Lira for northern, Kamuli for eastern and Kisoro for western. However, Kisoro was later eliminated because it was found to be using stones for construction while the bricks in the area are imported from other places and yet funds had been spent in traversing the place in search for artisan brick making sites. 


\subsubsection{Sampling Techniques, Size and Instruments}

The choice of burnt clay brick making area depended on getting a brick maker who also had a heap of clay from which he had used partly to make the already burnt clay brick. Such places were identified in Mukono and lira. Unfortunately, there was no brick maker who had clay and bricks in Kamuli. Therefore, there was no basis of comparison however, clay was picked from Kamuli for percentage chemical analysis of aluminium oxide $\left(\mathrm{Al}_{2} \mathrm{O}_{3}\right)$, silicon dioxide $\left(\mathrm{SiO}_{2}\right)$, iron three oxide $\left(\mathrm{Fe}_{2} \mathrm{O}_{3}\right)$ and calcium oxide (Cao) for raw clay.

Three representative samples of burnt clay bricks from each selected brick artisan making areas were obtained following procedures provided in IS- 5454 which states that for lot of 2002 to 10,000 bricks sample size for compressive strength, breaking load, transverse strength, bulk density, water absorption and efflorescence is taken as 5 pieces. However, 50 bricks were picked from each site to cater for possible damages in transit, handling and any eventualities. The burnt artisan local clay bricks were handpicked from artisan brick making places of Mukono and Lira

The clay samples from Mukono, Lira and Kamuli were loaded in sacks for easy transportation. The samples of natural clay and that of burnt clay bricks were durably and clearly labelled and delivered for storage. From the storage the natural wet clay was given two months to dry. After drying, lamped clay was broken into smaller particles and got packed in plastic bottles and delivered to Geology Laboratory of the Department of Geology and Petroleum studies of Makerere University for testing. Artisan clay bricks were packed and delivered to Materials Laboratory of Kyambogo University for testing. Water absorption and efflorescence test were carried out on the bricks.

\subsection{Artisan Brick Manufacturing Process in Uganda}

The following are the stages in which the Ugandan brick artisans do manufacture the clay bricks:

Visual identification of clay deposits in the area of operation

Mining of clay from clay deposits areas and heaping the mined clay.

Tempering of clay

Molding of brick units

Drying of molded brick

Burning of bricks and cooling

\subsubsection{Visual Clay Identification}

They do normally identify clay in lower plain areas of the swamp places as fine grained and sticky soils that get stuck in clothes and difficult to remove when wet but can be scraped when dry.

\subsubsection{Clay Mining}

The selected area for clay mining is first cleaned or un soiled at the top to remove most of the un desirable top soils which is always rich in pebbles and organic matters. Clay is mined by use of hand tools like spades, shovels, hoes and is placed in heaps for some days for it to dissipate the excess water it is mined with. Usually, the time allowed is between 3 to 7 days depending on the water content in the clay.

\subsubsection{Tempering of Clay}

This is the converting of the mined clay into homogeneous mix of the desired plasticity by mixing it thoroughly with proper quantities of water [13]. This process is done manually. Clay is thoroughly kneaded under feet of workers with gradual addition of water till desired homogeneity and plasticity is obtained.

\subsubsection{Molding of Bricks}

Molding is the process of making properly shaped bricks units from thoroughly tempered clay. In Uganda molding is done using hand molding. The quality of the tempered clay is made soft so that it can be molded into the required shapes conveniently. The brick is shaped from tempered clay and filled into the mold with little effort of pressing the clay into the mold on a table as shown in Figure 5. There after the molded brick is transferred to a leveled prepared ground using a wooden mold to make up green bricks.
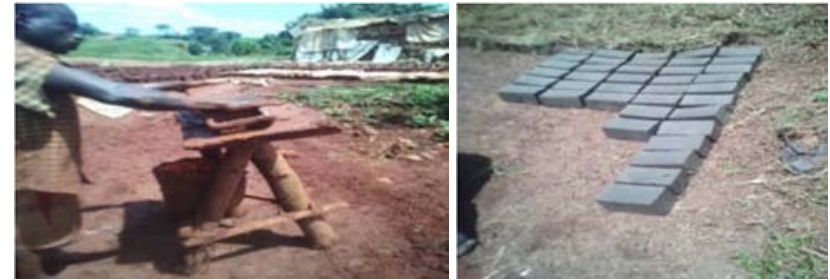

Figure 5. Artisan Method of Brick Molding.

\subsubsection{Drying of Molded Brick (Green Bricks)}

On removal from the mold the brick is rested on the largest plane for about 3 days and then changed to the smallest plane for about 4 days there after the bricks are stacked in an orderly format under a shade leaving gaps for aeration. In the shade, is where the green bricks gain strength before they become ready for firing or burning. After gain of strength and drying under the shade, the green bricks are stack in clamp style as shown in the field kiln for burning.

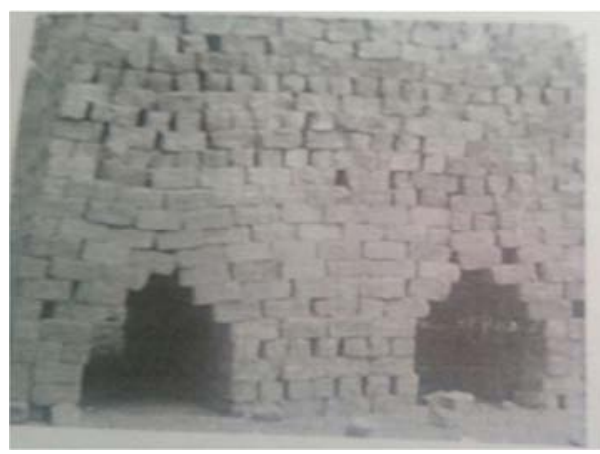

Figure 6. Field Kiln Burning of Bricks and Cooling.

After stacking the green bricks in a field kiln as shown in Figure 6, the fuel in form of firewood or agriculture waste e.g., coffee husks, rice husks, wood dust etc. are fed in the openings created in the field kiln. 
The field kilns are either rectangular or square. The sizes of the kiln around Kampala are between 2.1 to 3.0 meters in width and 3.5 to 6.0 metres in length. After feeding in either the husks or the fire wood then energized the fire for the firing to take place. At the beginning of firing, the wet grass is placed at the top of the field kiln. The firing time is prolonged until the wet grass at the top is burnt to ash. After the grass has got burnt, the opening in the field kiln are closed by use of mud mortar and the broken bricks, the sides of the field kiln also are covered by the mud mortar to avoid the loss of the heat.

\subsection{Testing Procedure}

Testing commenced with mineral content analysis of the natural clay from the areas of Mukono, Lira and Kamuli to confirm the percentage natural mineral existence of $\mathrm{Al}_{2} \mathrm{O}_{3}$, $\mathrm{Fe}_{2} \mathrm{O}_{3}, \mathrm{SiO}_{2}$ and $\mathrm{CaO}$. The natural clay was there after purified using slurry fractionating method taking advantage of different densities of the natural clay constituents in the slurry. After clay purification, the purified clay was analysed on the effect that had occurred on its mineral content rearrangement in the clay structure. Clay units were made from the purified clay using artisan method of moulding and bricks made from raw clay using relative uniform force mould, dried, baked and tested of compressive crushing strength, water absorption and efflorescence. The artisan bricks were also tested for compressive crushing strength, water absorption and efflorescence. Testing was done at Makerere University Department of Geology and Petroleum Studies Laboratory Uganda, Kyambogo University Civil Engineering Material Laboratory Uganda.

\subsubsection{Data Presentation}

Test results were presented on Standard Test Forms and summarised accordingly as shown in Appendix 1 to give a quicker overview in interpreting results. Further presentations were made in form of figures with representative graphs showing the overall behaviour of the materials.

\subsubsection{Data Analysis}

The test results obtained were analysed using Microsoft excel.

\subsection{Research Approach and Design}

This research was experimental since different types of clay and baked clay brick samples from different regions of Uganda were taken for laboratory testing to: -

1. Confirm and analyse percentage of natural mineral existence of $\mathrm{Al}_{2} \mathrm{O}_{3}, \mathrm{Fe}_{2} \mathrm{O}_{3}, \mathrm{SiO}_{2}$ and $\mathrm{CaO}$ and effect of purifying clay on the percentage existence of $\mathrm{Al}_{2} \mathrm{O}_{3}$, $\mathrm{Fe}_{2} \mathrm{O}_{3}, \mathrm{SiO}_{2}$ and $\mathrm{CaO}$.

2. Determination of compressive strength, absorption and efflorescence effects of the artisan bricks and new manufactured building clay units from purified clay to obtain the relationship between the artisan method of manufacturing, and the manufacturing method that involved clay purification.
3. Determine the purity level /response of clay from different regions of Uganda.

\subsection{Analysis for Natural and Purified Clay of the Percentage content of $\mathrm{Al}_{2} \mathrm{O}_{3}, \mathrm{Fe}_{2} \mathrm{O}_{3} \mathrm{SiO}_{2}$ and $\mathrm{CaO}$}

Samples were tested for percentage existence of $\mathrm{Al}_{2} \mathrm{O}_{3}$, $\mathrm{Fe}_{2} \mathrm{O}_{3} \quad \mathrm{SiO}_{2}$ and $\mathrm{CaO}$ in its natural and purified state to determine its conformity to the percentage required to produce the required product for engineering standards that make the brick stable, durable and strong.

\subsubsection{Objective}

Aluminate $\left(\mathrm{Al}_{2} \mathrm{O}_{3}\right)$, silicate $\left(\mathrm{SiO}_{2}\right)$, iron three oxide $\left(\mathrm{Fe}_{2} \mathrm{O}_{3}\right)$ and lime $(\mathrm{CaO})$ are the major constituents of the earth for brick making [10, 17]. These constituents must be in certain proportions for quality brick making [10, 13]. The major objective of the test was to measure the proportions of the constituents of clay, both in natural and purified state and compare with the required chemical clay composition for manufacturing of industrial ceramics that results in high strength, stability and durability.

\subsubsection{Significance}

The importance of carrying out the analysis for natural and purified clay of the percentage existence of $\mathrm{Al}_{2} \mathrm{O}_{3}, \mathrm{Fe}_{2} \mathrm{O}_{3}$ $\mathrm{SiO}_{2}$ and $\mathrm{CaO}$ was to know if the constituents of the clay in the regions selected were complying with the right proportions of the earth that produce the brick that is strong, chemically stable and durable.

\subsubsection{Apparatus}

Grinding machine

Digester

Automatic absorption spectrophotometer (Agilent 240FS AA)

\subsubsection{Procedure}

1. The clay sample was put in grinding machine and grounded to the powder form.

2. The clay powder was then mixed with aqua regia (mixture of hydrochloric acid and nitric acid) for digest.

3. The resultant solution/digest was then fixed to the chambers of the Absorption spectrophotometer (Agilent 240FS AA) for analysis.

\subsubsection{Observations}

Readings were recorded in standard form and results were expressed in parts per million (ppm) for both natural state and purified state and percentage were obtained as presented in appendix.

\subsection{Clay Purification}

The clay purification $[2,3]$ was to remove the free sand, coarse particles, organic materials and silt from natural clay and remain with bonded silicon dioxide and have significant increase in the aluminate in the composition of the clay samples after sand, coarse particles, organic matter and silt separated from the clay structure. 


\subsubsection{Significance}

The significance of the purification process was to confirm the clay structure that is good enough for manufacturing engineering products and separate the impurities of clay from pure clay.

\subsubsection{Test Apparatus}

Transparent 20 litre bucket

Closely weaved cloth

Stop Watch with accuracy of 0.1 s and

Mingling pad (stick)

\subsubsection{Test Procedure}

1. Three transparent buckets labelled A, B and C were used in each test.

2. In bucket $B$ and $C$ natural sample of the same type of clay was placed to approximately occupy $25 \%$ of each transparent bucket by volume.

3. Water was then topped on the natural clay to approximately filling to $90 \%$ of each bucket by volume.

4. The mingling pad was used to stir the clay to mix with water to make uniform clay slurry. Mingling took approximately 30 minutes for brown clay and light grey clay. For dark grey clay it took less than 30 minutes.

5. A third transparent bucket $A$ in each experiment was covered on top with a closely weaved cloth and secured firm with rubber band.

6. The clay slurry in bucket B was poured on top of the secured firm closely weaved cloth on top of Bucket A and the clay trapped on top of the cloth and left to settle and water drip through for 72 hours (3 days).

7. The slurry in bucket $\mathrm{C}$ was left to settle for 72 hours (3 days) to ensure that the clay structure separates from coarse particles, sand, organic materials and silt. The water on top was siphoned/ sucked off using a clear horse pipe. Data was recorded in a standard form for analysis.

\subsubsection{Observations}

1. The clay that was in bucket $\mathrm{C}$, was left settling and observed to have developed into layers.

2. The top most layer was clear water with floating organic materials

3. The second layer from top was smooth on touching and sticky

4. The third layer from top was smooth but not sticky on touching

5. The fourth layer from the top was coarse on touching and rough.

6. The smooth and sticky layer was scooped using hands from bucket $\mathrm{C}$ after siphoning/sucking off the clear water and is from which new building units were manufactured and referred as modified units.

7. The clay that was poured on top of the closely weaved cloth on bucket A was seen to allow slow dripping of water through the cloth and after three days a suspension was seen as a filtrate and at processes of pouring the slurry on the cloth, when the coarse materials started appearing onto the cloth, the pouring stop because the coarse materials are not found to be good.

8. The methods used for bucket $\mathrm{B}$ and that of $\mathrm{C}$, bucket $\mathrm{C}$ method was found to be more perfect because it ensures total separation compared to pouring which can lead to mix silt and sticky clay in the process of pouring since the silt is close to sticky clay in the slurry settling fractioning $[4,8]$.

9. The yield of the sticky layer was seen more in brown clay, seconded by light grey clay and was list in dark grey clay.

\subsection{Compressive Strength Test}

\subsubsection{Objective}

Compressive strength test is a mechanical test measuring the maximum amount of compressive load a material can bear before fracturing. The major objective of the test was to measure the maximum amount of load that the materials can carry/bear before fracturing i.e., the artisan brick, made brick from raw clay, modified brick from purified clay and compare their results of bearing capacity/characteristics strengths to see if the purification of the clay increases value in terms of strength, stability and durability.

\subsubsection{Significance}

The test was important in determining the level at which the purification of clay and relative uniform force moulding affects the bearing strength of the products manufactured from purified clay using artisan moulding methods and raw clay using relative uniform force moulding as compared to artisan brick.

\subsubsection{Sample Preparation}

The artisan clay brick samples were obtained from parent source and were ready for testing. The clay units from purified clay were moulded using artisan moulding style; bricks from raw clay moulded using improved mold shown in Figure 7, dried, and baked before tested.
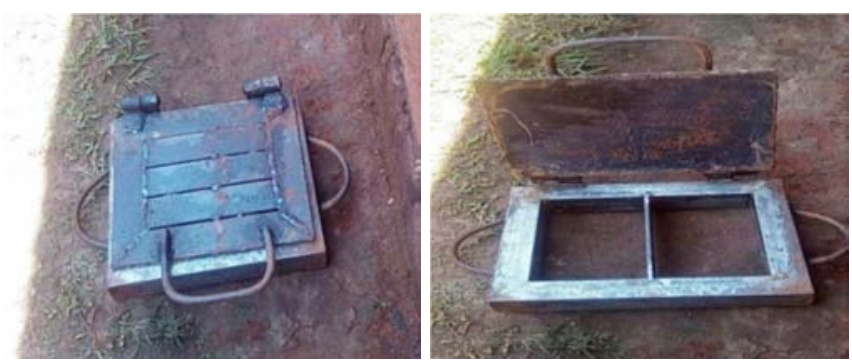

Figure 7. Improved Metal mold.

\subsubsection{Apparatus}

Hydraulic compressive testing machine

Steel measuring tape

Calculator

Note book

Pen 


\subsubsection{Procedure}

1. All the prepared material was assembled in the laboratory.

2. The dimensions of each brick in contact with the bearing surface were taken for each brick.

3. The bricks were placed on the bearing plate of the compression testing machine one at a time then the upper plate was lowered by the screw until it touched the brick. All the nobs that allow hydraulic force to be generated were closed and the pumping of the machine was then done to exert force on the brick which was placed between the bearing plate and the upper screwed plate. As the pumping continued a force in kilo newtons was registered on face plate. The force stopped being generated automatically when the fracture occurred in the brick and a reading was taken.

4. All contact surfaces and crushing forces for each brick were recorded in a standard form to allow calculation of crushing force for each brick.

5. Average crushing force for each type from different regions, manufactured bricks from purified \& raw clay and artisan was got for comparison.

\subsubsection{Reporting}

Contact surfaces of each brick to the bearing plates were recorded with corresponding forces readings that caused a fracture.

\subsection{Absorption Tests}

\subsubsection{Objective}

To determine the classification of the bricks (quality) produced by the artisans and improved chemical composition from purified clay and the effects of the extent to the bricks undergo during wet conditions (durability) and (weathering).

\subsubsection{Significance}

To determine the durability of the artisan improved chemical composition to the standard brick.

To classify the quality of the artisan, improved chemical composition to the standard brick.

To show the input of purifying the raw clay.

\subsubsection{Apparatus}

Electronic compact scale to accuracy of 0.01 gram

Transparent water container

Alarm clock

Note book

Pen

\subsubsection{Procedure}

1. Five bricks from artisan sites, five improved molded bricks and improved chemical composition clay units were selected from Mukono and Lira.

2. Each dry baked brick was cleaned of loose sand /clay and were marked 1,2,3,4 and 5 .

3. Each cleaned dry brick was weighed and the dry weight recorded as M1.

4. After recording the dry weight, all bricks were immersed in clean water for 24 hours After 24 hours of immersion all the bricks were wiped of water and immediately weighed and recorded M2.

5. Average weight for the dry and that of the wet were calculated.

6. From the averages the dry values and the wet values of the bricks, absorption was calculated as:

$$
\text { Absorption }=\frac{\{(\mathrm{M} 2-\mathrm{M} 1)\} \times 100}{\mathrm{M} 1}[12,16]
$$

\subsubsection{Reporting of Results}

The absorption of the bricks was recorded that lead to the classification of the bricks.

\subsection{Efflorescence}

\subsubsection{Objective}

Efflorescence is the migration of salt in a solution form from inner part to the surface of porous material, where it forms a coating. The major objective was to determine the presence of the alkalis in the bricks and the earth material that was used to manufacture the brick.

\subsubsection{Significance}

The test provided the knowledge of the detection of the alkalis that are dangerous to the building units as they affect the walls and construction at large. This test was important as it measures the resistance of the building materials' ability to absorb water that would bring dampness in the house and make the plastering of the walls peel off.

\subsubsection{Apparatus}

Transparent buckets

Alarm clock

Procedure

1. Five bricks were selected from each sample and the bricks were labelled bearing the name of their origin.

2. All the bricks were totally immersed in clean water for 24 hours

3. After 24 hours all were removed and placed under shade where there was enough air circulation.

4. After two weeks the brick surfaces were observed, to monitor salt migration that had occurred on their surfaces.

\subsubsection{Reporting}

Appearances of salts on the surface of the on the brick surface were reported. 


\section{Test Results from Experiments}

Table 1. Results of Percentage content of $\mathrm{Al}_{2} \mathrm{O}_{3}, \mathrm{Fe}_{2} \mathrm{O}_{3}, \mathrm{SiO}_{2}$ and $\mathrm{CaO}$ in Natural and Purified state.

\begin{tabular}{|c|c|c|c|c|c|c|c|}
\hline \multicolumn{8}{|c|}{ Results of Percentage Content of $\mathrm{Al}_{2} \mathrm{O}_{3}, \mathrm{Fe}_{2} \mathrm{O}_{3}, \mathrm{SiO}_{2}$ and $\mathrm{CaO}$ in Natural State } \\
\hline Sample Name & $\mathrm{Al}_{2} \mathrm{O}_{3}(\mathrm{ppm})$ & $\mathrm{Al}_{2} \mathrm{O}_{3} \%$ & $\mathrm{Fe}_{2} \mathrm{O}_{3}(\mathrm{ppm})$ & $\mathrm{Fe}_{2} \mathrm{O}_{3}(\%)$ & $\mathrm{CaO}$ (ppm) & $\mathrm{CaO}(\%)$ & $\mathrm{SiO}_{2}(\%)$ \\
\hline Lira Brown Clay & 17194.14 & 1.7 & 14956.15 & 1.5 & 13168.99 & 1.3 & 85.0 \\
\hline Lira Light Grey Clay & 22280.59 & 2.2 & 11194.83 & 1.1 & 5736.69 & 0.6 & 85.0 \\
\hline Lira Dark Grey Clay & 3008.80 & 0.3 & 5379.09 & 0.5 & 894.56 & 0.09 & 92.5 \\
\hline Mukono Brown Clay & 9214.02 & 0.9 & 18326.61 & 1.8 & 2088.20 & 0.2 & 91.2 \\
\hline Mukono Light Grey Clay & 11497.95 & 1.1 & 15502.82 & 1.6 & 4801.15 & 0.5 & 86.1 \\
\hline Mukono Dark Grey Clay & 6999.93 & 0.7 & 5799.11 & 0.6 & 18546.34 & 1.9 & 88.8 \\
\hline Kamuli Brown Clay & 12686.92 & 1.2 & 1.2 & 0.9 & 7466.67 & 0.7 & 88.2 \\
\hline Kamuli Light Grey Clay & 8191.01 & 0.8 & 2759.13 & 0.3 & 8726.62 & 0.9 & 68.4 \\
\hline Kamuli Dark Grey Clay & 6086.30 & 0.6 & 3681.57 & 0.4 & 1002.77 & 0.1 & 98.7 \\
\hline
\end{tabular}

\begin{tabular}{lllll}
\hline \multicolumn{7}{l}{ Results of Percentage Content of $\mathbf{A l}_{\mathbf{2}} \mathbf{O}_{\mathbf{3}}, \mathbf{F e}_{\mathbf{2}} \mathbf{O}_{\mathbf{3}} \mathbf{S i O}_{\mathbf{2}}$ and $\mathbf{C a O}$ in Purified Clay } & & \\
\hline Sample Name & $\mathbf{A l}_{\mathbf{2}} \mathbf{O}_{\mathbf{3}} \mathbf{\%}$ & $\mathbf{F e}_{\mathbf{2}} \mathbf{O}_{\mathbf{3}} \mathbf{( \% )}$ & $\mathbf{C a O} \mathbf{( \% )}$ & $\mathbf{S i O}_{\mathbf{2}}(\mathbf{\%})$ \\
\hline Lira Brown Clay & 2.95 & 1.66 & 0.1 & 76.7 \\
Lira Light Grey Clay & 2.63 & 1.66 & 0.04 & 80.4 \\
Lira Dark Grey Clay & 2.02 & 1.41 & 0.04 & 95.98 \\
Mukono Brown Clay & 2.42 & 3.73 & 0.09 & 89.3 \\
Mukono Light Grey Clay & 1.5 & 1.73 & 0.06 & 79.4 \\
Mukono Dark Grey Clay & 1.99 & 2.04 & 0.01 & 83.7 \\
\hline
\end{tabular}

Table 2. Compressive Test results for bricks from Lira.

\begin{tabular}{|c|c|c|c|c|c|}
\hline \multicolumn{6}{|c|}{ Compressive Tests Results for Artisan Common Clay Brick from Lira } \\
\hline Item & Size of brick (mm) & Weight of brick(kg) & Area of brick $\left(\mathrm{mm}^{2}\right)$ & $\begin{array}{l}\text { Compressive crushing } \\
\text { force read x1000N }\end{array}$ & $\begin{array}{l}\text { Ultimate compressive } \\
\text { strength }\left(\mathrm{N} / \mathrm{mm}^{2}\right)\end{array}$ \\
\hline 1 & $210 \times 135$ & 3.4 & 28,350 & 58.6 & 2.06 \\
\hline 3 & $210 \times 135$ & 3.2 & 28,350 & 29.5 & 1.04 \\
\hline 5 & $210 \times 135$ & 3 & 28,350 & 35.29 & 1.24 \\
\hline 6 & $210 \times 135$ & 3.4 & 28,350 & 38.28 & 1.35 \\
\hline 8 & $210 \times 135$ & 3.2 & 28,350 & 23.49 & 0.83 \\
\hline \multicolumn{6}{|c|}{ Characteristic strength of artisan clay brick from Lira is $0.63 \mathrm{~N} / \mathrm{mm}^{2}$ from calculations } \\
\hline
\end{tabular}

\begin{tabular}{|c|c|c|c|c|c|}
\hline \multicolumn{6}{|c|}{ Compressive Tests Results for Improved Moldings Brick from Raw Clay Lira } \\
\hline Item & Size of brick(mm) & Weight of the brick(kg) & $\begin{array}{l}\text { Area of brick } \\
\left(\mathrm{mm}^{2}\right)\end{array}$ & $\begin{array}{l}\text { Compressive crushing } \\
\text { force read } \times 1000 \mathrm{~N}\end{array}$ & $\begin{array}{l}\text { Ultimate compressive } \\
\text { strength }\left(\mathrm{N} / \mathrm{mm}^{2}\right)\end{array}$ \\
\hline 1 & $180 \times 107$ & 2.0 & 19260 & 131 & 6.8 \\
\hline 2 & $180 \times 107$ & 2.3 & 19260 & 93 & 4.8 \\
\hline 3 & $180 \times 107$ & 2.3 & 19260 & 65.5 & 3.4 \\
\hline 4 & $180 \times 107$ & 2.3 & 19260 & 95 & 4.9 \\
\hline 5 & $180 \times 107$ & 2.3 & 19260 & 80 & 4.2 \\
\hline \multicolumn{6}{|c|}{ Characteristic strength of improved moldings brick from raw clay Lira is $3.3 \mathrm{~N} / \mathrm{mm}^{2}$ from calculations } \\
\hline
\end{tabular}

\begin{tabular}{|c|c|c|c|c|c|}
\hline \multicolumn{6}{|c|}{ Compressive Tests Results for Improved Chemical Composition Artisan Unit from Purified Lira Light Grey Clay } \\
\hline Item & Size of clay unit & Area of clay & $\begin{array}{l}\text { Compressive crushing } \\
\text { force read x1000N }\end{array}$ & $\begin{array}{l}\text { Ultimate compressive } \\
\text { strength }\left(\mathrm{N} / \mathrm{mm}^{2}\right)\end{array}$ & $\begin{array}{l}\text { Average compressive } \\
\text { strength }(\mathrm{N} / \mathrm{mm} 2)\end{array}$ \\
\hline 1 & $\varnothing 70 \mathrm{~mm} \& 75 \mathrm{~mm}$ thick & 3848.45 & 10.3 & 2.68 & \\
\hline 2 & $\varnothing 70 \mathrm{~mm} \& 75 \mathrm{~mm}$ thick & 3848.45 & 10.6 & 2.75 & \\
\hline 3 & $\varnothing 70 \mathrm{~mm} \& 75 \mathrm{~mm}$ thick & 3848.45 & 5.2 & 1.359 (not considered) & 2.75 \\
\hline 4 & $\varnothing 70 \mathrm{~mm} \& 75 \mathrm{~mm}$ thick & 3848.45 & 13.3 & 3.45 & \\
\hline 5 & $\varnothing 70 \mathrm{~mm} \& 75 \mathrm{~mm}$ thick & 3848.45 & 8.1 & 2.1 & \\
\hline \multicolumn{6}{|c|}{ Characteristic strength of improved chemical composition artisan unit from purified Lira light grey clay is $2.0 \mathrm{~N} / \mathrm{mm}^{2}$ from calculations } \\
\hline
\end{tabular}

Table 3. Compressive Test Results for bricks from Mukono

\begin{tabular}{llllll}
\hline \multicolumn{6}{l}{ Compressive Tests Results for Artisan Common Clay Brick from Mukono } \\
\hline Item & Size of brick & Weight of the brick $(\mathbf{k g})$ & Area of brick $\left(\mathbf{m m}^{\mathbf{2}}\right)$ & $\begin{array}{l}\text { Compressive crushing force } \\
\text { read x1000N }\end{array}$ & $\begin{array}{l}\text { Ultimate compressive strength } \\
\left(\mathbf{N} / \mathbf{m m}^{2}\right)\end{array}$ \\
\hline 1 & $200 \times 110$ & 3.8 & 22,000 & 14.7 & 0.67 \\
2 & $200 \times 110$ & 3.4 & 22,000 & 35 & 1.59 \\
\hline
\end{tabular}




\begin{tabular}{llllll}
\hline \multicolumn{6}{l}{ Compressive Tests Results for Artisan Common Clay Brick from Mukono } \\
\hline Item & Size of brick & Weight of the brick $\mathbf{( k g )}$ & Area of brick $\left.\mathbf{( m m}^{2}\right)$ & $\begin{array}{l}\text { Compressive crushing force } \\
\text { read x1000N }\end{array}$ & $\begin{array}{l}\text { Ultimate compressive strength } \\
\left(\mathbf{N} / \mathbf{m m}^{2}\right)\end{array}$ \\
\hline 3 & $200 \times 110$ & 3.1 & 22,000 & 19.4 & 0.88 \\
4 & $200 \times 110$ & 2.8 & 22,000 & 50 & 2.27 \\
5 & $200 \times 110$ & 3.8 & 22,000 & 58.9 & 2.68 \\
\multicolumn{7}{l}{ Characteristic strength of Mukono artisan clay brick is $0.38 \mathrm{~N} / \mathrm{mm}^{2}$} & & \\
\hline
\end{tabular}

\begin{tabular}{llllll}
\hline \multicolumn{7}{l}{ Compressive Tests Results for Improved Molding Brick from Raw Clay Mukono } \\
\hline Item & Size of brick & Weight of the brick (kg) & Area of brick $\mathbf{( m m}^{2}$ ) & $\begin{array}{l}\text { Compressive crushing } \\
\text { force read x1000N }\end{array}$ & $\begin{array}{l}\text { Ultimate compressive } \\
\text { strength }\left(\mathbf{N} / \mathbf{m m}^{2}\right)\end{array}$ \\
\hline 1 & $180 \times 107$ & 1.9 & 19260 & 15.7 & 0.82 \\
2 & $180 \times 107$ & 2 & 19260 & 147.6 & 7.66 \\
3 & $180 \times 107$ & 2 & 19260 & 97.4 & 3.05 \\
4 & $180 \times 107$ & 1.8 & 19260 & 64.9 & 1.05 \\
5 & $180 \times 107$ & 2 & 19260 & 20.2 & \\
\multicolumn{7}{l}{ Characteristic strength of improved molding brick from raw clay Mukono is 2.62N/mm2 from calculations } \\
\hline
\end{tabular}

\begin{tabular}{|c|c|c|c|c|c|}
\hline \multicolumn{6}{|c|}{ Compressive Tests Results for Improved Chemical Composition Artisan Clay Unit from Purified Mukono Brown Clay } \\
\hline Item & Size of clay unit & $\begin{array}{l}\text { Area of clay } \\
\text { unit }\end{array}$ & $\begin{array}{l}\text { Compressive crushing } \\
\text { force read x1000N }\end{array}$ & $\begin{array}{l}\text { Ultimate compressive } \\
\text { strength }\left(\mathrm{N} / \mathbf{m m}^{2}\right)\end{array}$ & $\begin{array}{l}\text { Average compressive } \\
\text { strength }\left(\mathrm{N} / \mathbf{m m}^{2}\right)\end{array}$ \\
\hline 1 & $\varnothing 70 \mathrm{~mm} \& 75 \mathrm{~mm}$ thick & 3848.45 & 18.2 & 4.70 & \multirow{5}{*}{7.65} \\
\hline 2 & Ø $70 \mathrm{~mm} \& 75 \mathrm{~mm}$ thick & 3848.45 & 29.1 & 7.56 & \\
\hline 3 & $\varnothing 70 \mathrm{~mm} \& 75 \mathrm{~mm}$ thick & 3848.45 & 35.9 & 9.33 & \\
\hline 4 & $\varnothing 70 \mathrm{~mm} \& 75 \mathrm{~mm}$ thick & 3848.45 & 31.8 & 8.26 & \\
\hline 5 & $\varnothing 70 \mathrm{~mm} \& 75 \mathrm{~mm}$ thick & 3848.45 & 32.4 & 8.4 & \\
\hline \multicolumn{6}{|c|}{ Characteristic strength of improved chemical composition artisan clay unit from Purified Mukono Brown Clay is $5.12 \mathrm{~N} / \mathrm{mm} 2$ from calculations } \\
\hline
\end{tabular}

Table 4. Water Absorption Test Results for Bricks from Lira.

\begin{tabular}{|c|c|c|c|c|c|c|c|}
\hline \multicolumn{8}{|c|}{ Water Absorption Test Results for Artisan Bricks from Lira } \\
\hline SN & $\mathbf{L}(\mathbf{m m})$ & B (mm) & $\mathbf{H}(\mathbf{m m})$ & $\begin{array}{l}\text { Weight of } \\
\text { dry brick }\end{array}$ & $\begin{array}{l}\text { Average weight of } \\
\text { dry brick (M1) }\end{array}$ & $\begin{array}{l}\text { Weight of } \\
\text { wet brick }\end{array}$ & $\begin{array}{l}\text { Average weight of } \\
\text { wet brick (M2) }\end{array}$ \\
\hline 1 & 205 & 135 & 66 & 3239.9 & \multirow{6}{*}{3217.44} & 3720.2 & \multirow{6}{*}{3754.3} \\
\hline 2 & 205 & 135 & 60 & 3039.2 & & 3515.2 & \\
\hline 3 & 215 & 141 & 68 & 3555.4 & & 3535.4 & \\
\hline 4 & 211 & 135 & 61 & 3092.7 & & 4023.9 & \\
\hline 5 & 210 & 139 & 62 & 3160 & & 3976.8 & \\
\hline & & & & 16087.2 & & 18771.5 & \\
\hline
\end{tabular}

\begin{tabular}{llllll}
\hline \multicolumn{6}{l}{ Water Absorption Test Results for improved chemical composition unit from Purified Lira Light Grey Clay } \\
\hline SN & Size of clay unit & $\begin{array}{l}\text { Weight of dry clay } \\
\text { unit (grms) }\end{array}$ & $\begin{array}{l}\text { Average weight of dry } \\
\text { clay unit(M1) grms }\end{array}$ & $\begin{array}{l}\text { Weight of wet clay } \\
\text { unit (grms) }\end{array}$ & $\begin{array}{l}\text { Average weight of wet clay } \\
\text { unit (grms) (M2) }\end{array}$ \\
\hline 1 & $\varnothing 70 \mathrm{~mm}$ & 318 & & 345.5 & \\
2 & $\varnothing 70 \mathrm{~mm}$ & 298.5 & 334.4 & 371.3 & 388.6 \\
3 & $\varnothing 70 \mathrm{~mm}$ & 347.7 & & 387.6 & \\
4 & $\varnothing 70 \mathrm{~mm}$ & 333.7 & & 432.3 & \\
5 & $\varnothing 70 \mathrm{~mm}$ & 374.2 & &
\end{tabular}

Table 5. Efflorescence Test Results on Artisan, Improved chemical composition artisan and Improved Mould Bricks of Mukono and Lira.

\begin{tabular}{llllll}
\hline Item & Description & $\begin{array}{l}\text { Area of brick } \\
\left.\text { surface } \mathbf{( m m}^{2}\right)\end{array}$ & $\begin{array}{l}\text { Area seen with } \\
\text { whitish/greyish shades }\end{array}$ & $\begin{array}{l}\text { Percentage of area of brick } \\
\text { with efflorescence effect }\end{array}$ & $\begin{array}{l}\text { Result of efflorescence } \\
{[\mathbf{9 , 1 3 , 1 6 ]}}\end{array}$ \\
\hline 1 & Mukono artisan brick & 20,000 & 4000 & $20 \%$ & Moderate \\
2 & Lira artisan brick & 29400 & 4500 & $15.30 \%$ & Moderate \\
3 & Improved chemical artisan brick Mukono & 3848.5 & 225 & $6 \%$ & Slight \\
4 & Improved chemical artisan brick Lira & 3848.5 & 2475 & $12.3 \%$ & Moderate \\
5 & Improved mould brick Mukono & 19260 & 2899 & $15 \%$ & Moderate \\
6 & Improved mould brick Lira & 19270 & 2696.4 & $14 \%$ & Moderate \\
\hline
\end{tabular}




\section{Discussions and Conclusions}

\subsection{Discussions}

Table 6. Percentage sum of Aluminate and Silicon dioxide in Natural Sample.

\begin{tabular}{|c|c|c|c|c|c|}
\hline Sample name & $\mathrm{Al}_{2} \mathrm{O}_{3}(\%)$ & $\mathrm{SiO}_{2}(\%)$ & Percentage sum of aluminate $\&$ silicon dioxide & Acceptable range (75-84\%) [10] & Remarks \\
\hline Lira Brown Clay & 1.7 & 90.0 & $91.7 \%$ & $75-84 \%$ & Above Max. \\
\hline Lira Light Grey Clay & 2.2 & 85.0 & $87.2 \%$ & $75-84 \%$ & Above Max. \\
\hline Lira Dark Grey Clay & 0.3 & 92.5 & $92.8 \%$ & $75-84 \%$ & Above Max. \\
\hline Mukono Brown Clay & 0.9 & 91.2 & $92.1 \%$ & $75-84 \%$ & Above Max. \\
\hline Mukono light grey Clay & 1.1 & 86.1 & $87.2 \%$ & $75-84 \%$ & Above Max. \\
\hline Mukono dark grey Clay & 0.7 & 88.8 & $89.5 \%$ & $75-84 \%$ & Above Max. \\
\hline Kamuli Brown Clay & 1.2 & 88.2 & $89.4 \%$ & $75-84 \%$ & Above Max. \\
\hline Kamuli light grey Clay & 0.8 & 68.4 & $69.2 \%$ & $75-84 \%$ & Below minimum \\
\hline Kamuli dark grey Clay & 0.6 & 98.7 & $99.3 \%$ & $75-84 \%$ & Above Max. \\
\hline
\end{tabular}

The results in this table all indicates that the available clay used by the artisan in Uganda was not good and it requires refining before is used for brick making.

Table 7. Percentage sum of Aluminate and Silicon dioxide in Purified Samples.

\begin{tabular}{|c|c|c|c|c|c|}
\hline Sample Name & $\mathrm{Al}_{2} \mathrm{O}_{3}(\%)$ & $\mathrm{SiO}_{2}(\%)$ & $\begin{array}{l}\text { Percentage sum of } \\
\text { aluminate silicon dioxide }\end{array}$ & $\begin{array}{l}\text { Acceptable range } \\
(75-84 \%)[10]\end{array}$ & Remarks \\
\hline Lira Brown Clay & 2.95 & 76.7 & 79.65 & $75-84 \%$ & Btn 75-84(ok) \\
\hline Lira Light Grey Clay & 2.63 & 80.03 & 83.03 & $75-84 \%$ & Btn 75-84(ok) \\
\hline Lira Dark Grey Clay & 2.02 & 95.98 & 98 & $75-84 \%$ & Above 84 (not ok) \\
\hline Mukono Brown Clay & 2.42 & 89.3 & 91.72 & $75-84 \%$ & Above $84 \%$ (not ok) \\
\hline Mukono light grey Clay & 1.5 & 79.4 & 80.9 & $75-84 \%$ & Btn 75-84(ok) \\
\hline Mukono dark grey Clay & 1.99 & 83.7 & 85.69 & $75-84 \%$ & (ok) \\
\hline
\end{tabular}

The results in this table indicates that the refining of the clay by use of slurry fractionation method improves the clay to better manufacturing chemical composition

Table 8. Comparison of Percentage Content of $\mathrm{Al}_{2} \mathrm{O}_{3}, \mathrm{Fe}_{2} \mathrm{O}_{3} \mathrm{SiO}_{2}$ and $\mathrm{CaO}$ in Natural and Purified State of Clays of Lira and Mukono.

\begin{tabular}{|c|c|c|c|c|}
\hline Sample Name & Chemical Name & $\begin{array}{l}\% \text { Composition in } \\
\text { natural state }\end{array}$ & $\begin{array}{l}\% \text { Composition } \\
\text { after purification }\end{array}$ & $\begin{array}{l}\text { \% Acceptable range for ideal industrial } \\
\text { manufacture of clay bricks }[6,10,13]\end{array}$ \\
\hline \multirow[t]{4}{*}{ Lira Light grey clay } & $\mathrm{Al}_{2} \mathrm{O}_{3}$ & 2.2 & 2.63 & $20-30$ \\
\hline & $\mathrm{Fe}_{2} \mathrm{O}_{3}$ & 1.1 & 1.66 & $4-6$ \\
\hline & $\mathrm{SiO}_{2}$ & 85 & 80.4 & $55-70$ \\
\hline & $\mathrm{CaO}$ & 0.6 & 0.04 & $\leq 4$ \\
\hline \multirow[t]{4}{*}{ Lira dark grey clay } & $\mathrm{Al}_{2} \mathrm{O}_{3}$ & 0.3 & 2.02 & $20-30$ \\
\hline & $\mathrm{Fe}_{2} \mathrm{O}_{3}$ & 0.5 & 1.41 & $4-6$ \\
\hline & $\mathrm{SiO}_{2}$ & 92.5 & 95.98 & $55-70$ \\
\hline & $\mathrm{CaO}$ & 0.09 & 0.04 & $\leq 4$ \\
\hline \multirow[t]{4}{*}{ Lira brown clay } & $\mathrm{Al}_{2} \mathrm{O}_{3}$ & 1.7 & 2.95 & $20-30$ \\
\hline & $\mathrm{Fe}_{2} \mathrm{O}_{3}$ & 1.5 & 2.55 & $4-6$ \\
\hline & $\mathrm{SiO}_{2}$ & 90 & 76.7 & $55-70$ \\
\hline & $\mathrm{CaO}$ & 1.3 & 0.1 & $\leq 4$ \\
\hline \multirow[t]{4}{*}{ Mukono Light grey clay } & $\mathrm{Al}_{2} \mathrm{O}_{3}$ & 1.1 & 1.5 & $20-30$ \\
\hline & $\mathrm{Fe}_{2} \mathrm{O}_{3}$ & 1.6 & 1.73 & $4-6$ \\
\hline & $\mathrm{SiO}_{2}$ & 86.1 & 79.4 & $55-70$ \\
\hline & $\mathrm{CaO}$ & 0.5 & 0.06 & $\leq 4$ \\
\hline \multirow[t]{4}{*}{ Mukono dark grey clay } & $\mathrm{Al}_{2} \mathrm{O}_{3}$ & 0.7 & 1.99 & $20-30$ \\
\hline & $\mathrm{Fe}_{2} \mathrm{O}_{3}$ & 0.6 & 2.04 & $4-6$ \\
\hline & $\mathrm{SiO}_{2}$ & 88.8 & 83.7 & $55-70$ \\
\hline & $\mathrm{CaO}$ & 1.9 & 0.01 & $\leq 4$ \\
\hline \multirow[t]{4}{*}{ Mukono brown clay } & $\mathrm{Al}_{2} \mathrm{O}_{3}$ & 0.9 & 2.42 & $20-30$ \\
\hline & $\mathrm{Fe}_{2} \mathrm{O}_{3}$ & 1.8 & 3.73 & $4-6$ \\
\hline & $\mathrm{SiO}_{2}$ & 91.2 & 89.3 & $55-70$ \\
\hline & $\mathrm{CaO}$ & 0.2 & 0.09 & $\leq 4$ \\
\hline
\end{tabular}




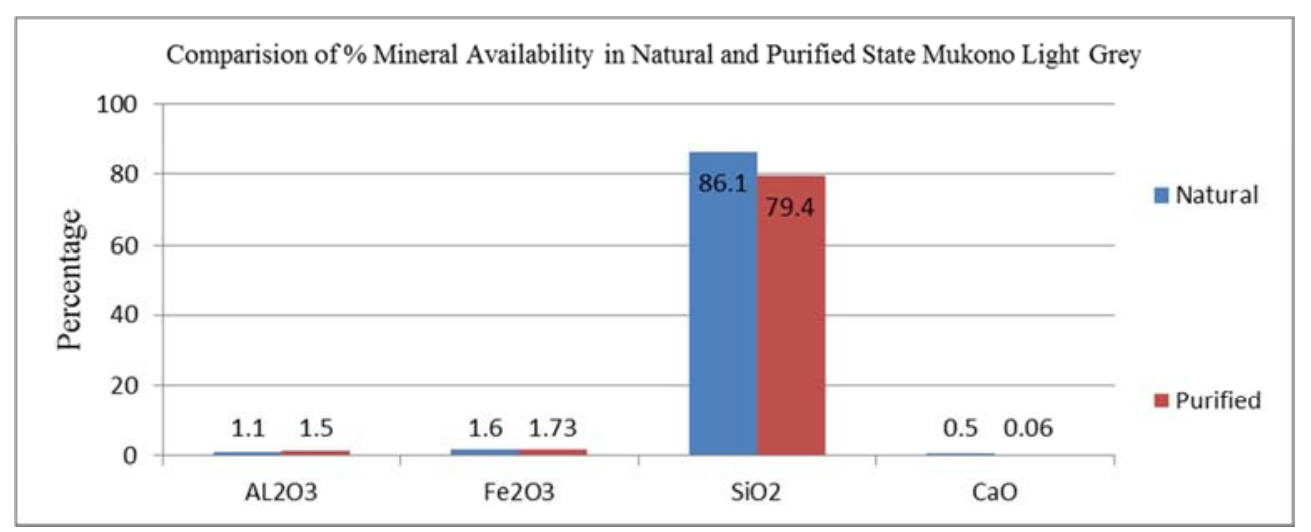

Figure 8. Comparison of Mineral Availability in Natural and Purified State Mukono Light grey.

When purification was applied on both lira and Mukono clays, there was increase in Aluminate and Iron three oxide and decrease in silicon dioxide and calcium oxide as compared raw clay. This kind of analogy was good because comparing with the raw clay mineral structure, the refining shifted the clay structure positively. Silicon dioxide is responsible for strength, hardness, resistance to shrinkage, shape of the brick and for durability is required in $55-70 \%$ for industrial ceramic manufacturing [10]. Mukono light grey was purified, silicon reduced from $86.6 \%$ to $79.4 \%$, (unbonded) silicon was reduced in the raw clay by $7.2 \%$ hence increase in strength, hardness, resistance to shrinkage and durability. Aluminate is responsible for plastic character required in $20-30 \%[10,13]$ increased from $1.1 \%$ to $1.5 \%$, increase by $0.4 \%$ hence plasticity nature of the clay structure increased.

$\mathrm{CaO}$ is a flux agent responsible for lowering down the softening temperature of the silica and quicker hardening of brick, is required in the amount of maximum of $4 \%[13]$. Reduction in the Cao from 0.5 to $0.06 \%$ is positive because much of $\mathrm{CaO}$ causes excessive softening which imparts lower strength. Disassociation of Cao in the solution during fractionation is an indication of reduction in efflorescence effects of the resulting product as too much of $\mathrm{CaO}$ would cause hydration that result in easy disintegration of the brick [13]. Iron three oxide is responsible for imparting color to the brick and is required in the range of $4-6 \%$ [13]. Increase on Iron three oxide from 1.6 to $1.73 \%$ is positive and an indication of increasing the quality of color of the resulting product after purification of raw clay.

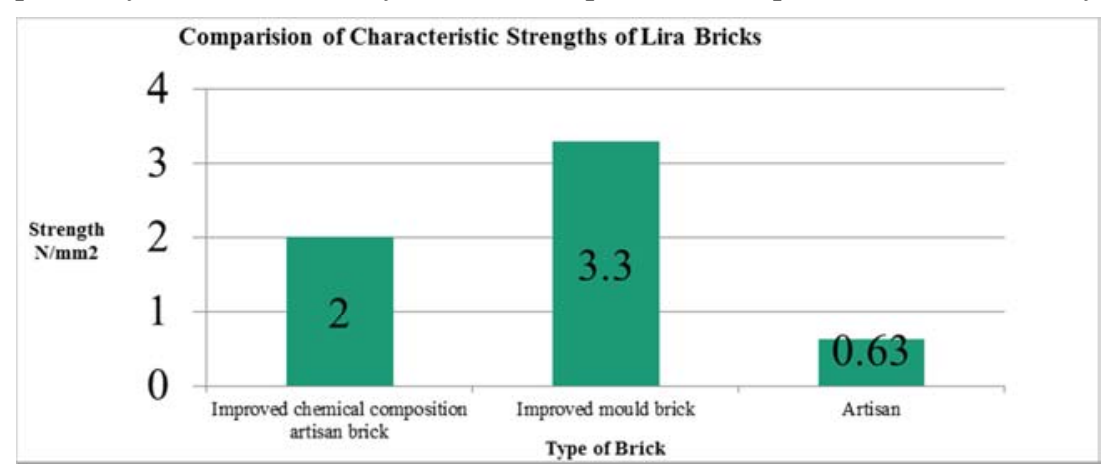

Figure 9. Comparison of characteristic strengths of Lira bricks.

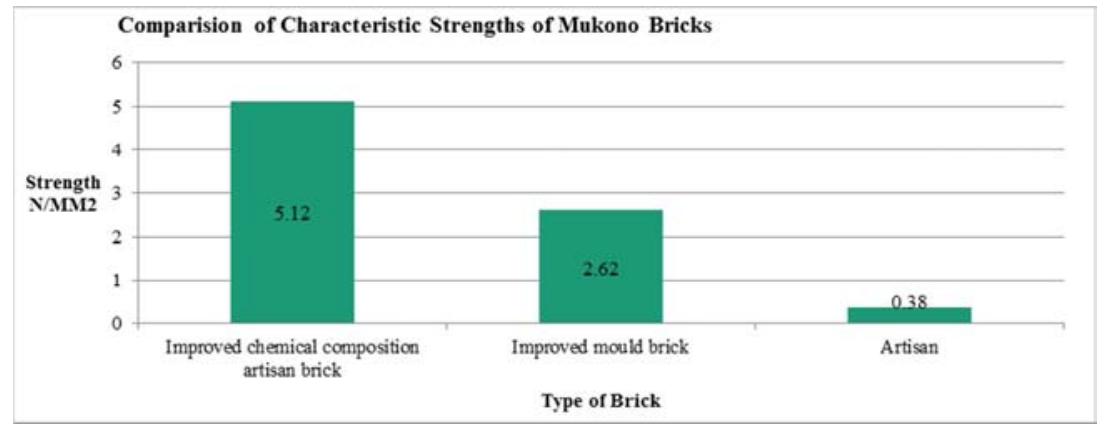

Figure 10. Comparison of characteristic strengths of Mukono bricks.

Characteristic strength of the Mukono artisan brick improved from $0.38 \mathrm{~N} / \mathrm{mm}^{2}$ to $2.62 \mathrm{~N} / \mathrm{mm}^{2}$ using improved mold then from $0.38 \mathrm{~N} / \mathrm{mm}^{2}$ to $5.12 \mathrm{~N} / \mathrm{mm}^{2}$ using improved chemical composition and artisan molding. The same 
operations were done on Lira clay and improvement was from $0.63 \mathrm{~N} / \mathrm{mm}^{2}$ to $3.3 \mathrm{~N} / \mathrm{mm}^{2}$ using improved mold then from $0.63 \mathrm{~N} / \mathrm{mm}^{2}$ to $2.0 \mathrm{~N} / \mathrm{mm}^{2}$ using improved chemical composition and artisan molding. Both Lira and Mukono bricks show that the method of purifying clay and use improved molding of bricks increases the characteristic values of the artisan brick.

Table 9. Water absorption for classification of bricks.

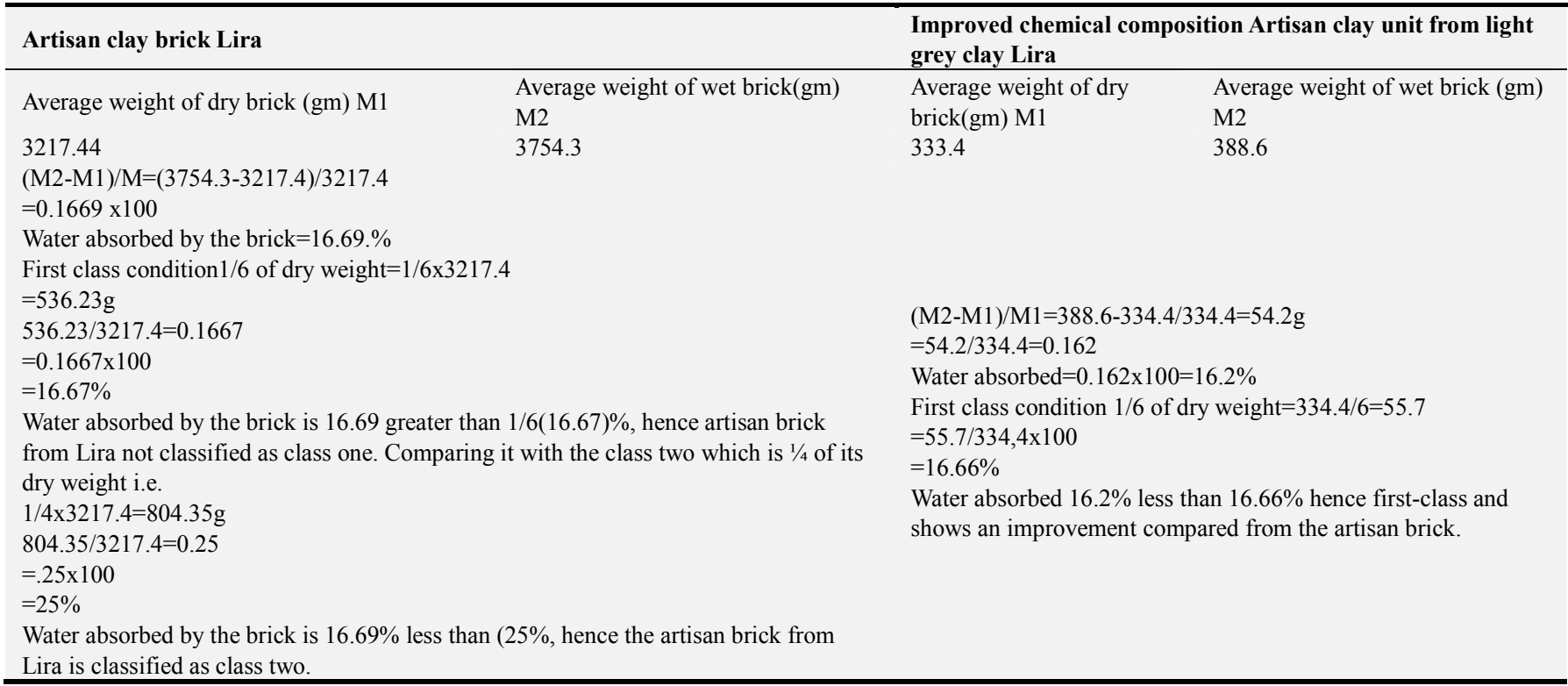

From this table of calculations, it is deduced that the slurry fractionation improves the class of the brick. This was the same with the Mukono clays.

Table 10. Efflorescence Test Results on Artisan, Improved chemical composition artisan and Improved Mould Bricks of Mukono and Lira.

\begin{tabular}{|c|c|c|c|c|c|}
\hline Item & Description & $\begin{array}{l}\text { Area of brick } \\
\text { surface }\left(\mathrm{mm}^{2}\right)\end{array}$ & $\begin{array}{l}\text { Area seen with } \\
\text { whitish/greyish shades }\end{array}$ & $\begin{array}{l}\text { Percentage of area of brick } \\
\text { with efflorescence effect }\end{array}$ & $\begin{array}{l}\text { Result of efflorescence } \\
{[9,13,16]}\end{array}$ \\
\hline 1 & Mukono artisan brick & 20,000 & 4000 & $20 \%$ & Moderate \\
\hline 2 & Lira artisan brick & 29400 & 4500 & $15.30 \%$ & Moderate \\
\hline 3 & Improved chemical artisan brick Mukono & 3848.5 & 225 & $6 \%$ & Slight \\
\hline 4 & Improved chemical artisan brick Lira & 3848.5 & 2475 & $12.3 \%$ & Moderate \\
\hline 5 & Improved mould brick Mukono & 19260 & 2899 & $15 \%$ & Moderate \\
\hline
\end{tabular}

From this result table of efflorescence, it indicates that Mukono artisan brick had $20 \%$ covered by salt migration. After slurry fractionation, $\%$ coverage reduced to $6 \%$. This reduction has been due to the disassociation of the salts and were eliminated as hydroxides hence reduction on the ability of the brick from absorbing much water which makes it of better class than before. The same happened with the Lira brick reduced from $15.3 \%$ to $12.3 \%$.

\subsection{Conclusions}

The methods followed by the artisans in manufacturing of the clay bricks was established and found unsatisfactory

The earth chemical percentage composition of $\left(\mathrm{Al}_{2} \mathrm{O}_{3}\right.$, $\mathrm{SiO}_{2}, \mathrm{Fe}_{2} \mathrm{O}_{3}$ and $\mathrm{CaO}$ ) used by the artisan in manufacturing clay bricks in Uganda was found.

Improvement on the percentage chemical of $\left(\mathrm{Al}_{2} \mathrm{O}_{3}, \mathrm{SiO}_{2}\right.$, $\mathrm{Fe}_{2} \mathrm{O}_{3}$ and $\mathrm{CaO}$ ) was achieved in line with ideal composition for quality production through use of slurry fractionation.

Refining of raw clay using slurry fractionation method and making bricks through use of constant force pressing molding is required as an intervention in the artisan manufacturing process to meet improved specific characteristic properties for durability, chemical stability and higher characteristic strength of clay bricks.

\subsection{Recommendations}

The study recommends an intervention of refining raw clay and use of constant force pressing in molding of bricks in the artisan method on manufacturing to produce good quality clay brick for durability, chemical stability and higher required characteristic strength for design specification.

The Research recommends Ugandan Government to map areas rich in kaolinite clays in every sub-county to help artisans, access better quality of clay for better quality brick manufacturing. Research recommends artisans to get training in clay brick manufacturing before engaging in manufacturing.

Recommend further research on clay for production of 
structural pre-stressed sections and medicinal activities on skin diseases.

\section{References}

[1] Abbas, S., Saleem, M. A., Kazmi, S. M. and Munir, M. J., 2017. Production of sustainable clay bricks using waste fly ash: mechanical and durability properties. Journal of Building Engineering, 14, pp. 7-14.

[2] Adnan, M., Sazzad, H. M. and Fakhrul, I. M., 2011. Potential of locally available clay as raw material for traditionalceramic. Journal of Chemical Engineering, The Institution of Engineers, Bangladesh, 26 (1), pp. 34-37.

[3] Ara, H., Zaman, T. and Kurny, A. S. W., Separation of Silica from Local Clay.

[4] Bain, J. A., 1971. A plasticity chart as an aid to the identification and assessment of industrial clays. Clay Minerals, 9 (1), pp. 1-17.

[5] Brick Industry Association, 2006. Technical notes on brick construction. Manufacturing of brick. The Brick Industry Association, Reston, VA.

[6] Chidiac, S. E. and Federico, L. M., 2007. Effects of waste glass additions on the properties and durability of fired clay brick. Canadian Journal of Civil Engineering, 34 (11), pp. 1458-1466.

[7] Dalkılıç, N. and Nabikoğlu, A., 2017. Traditional manufacturing of clay brick used in the historical buildings of Diyarbakir (Turkey). Frontiers of Architectural Research, 6(3), pp. 346-359.

[8] Dang, L. C., Khabbaz, H. and Fatahi, B., 2017, January. An experimental study on engineering behavior of lime and bagasse fibre reinforced expansive soils. In ICSMGE 2017- 19th International Conference on Soil Mechanics and Geotechnical Engineering.

[9] Dhir, R. K. and Jackson, N. eds., 1996. Civil engineering materials. Macmillan.

[10] Federico, L. M., Chidiac, S. E., \& Drysdale, R. G. (2005, June). The use of waste material in the manufacturing of clay brick. In Proceedings of the 10th Canadian Masonry Symposium, Banff, Alta (pp. 8-12).

[11] Hashemi, A., Cruickshank, H. and Cheshmehzangi, A., 2015. Environmental impacts and embodied energy of construction methods and materials in low-income tropical housing. Sustainability, 7 (6), pp. 7866-7883.

[12] https://civilconstructionresourcez.wordpress.com/.

[13] https://civilseek.com/manufacturing-of-bricks/.

[14] Johari, I., Said, S., Hisham, B., Bakar, A. and Ahmad, Z. A., 2010. Effect of the change of firing temperature on microstructure and physical properties of clay bricks from Beruas (Malaysia). Science of Sintering, 42 (2), pp. 245-254.

[15] Karaman, S., Ersahin, S. and Gunal, H., 2006. Firing temperature and firing time influence on mechanical and physical properties of clay bricks.

[16] Khanna, P. N., 2008. Civil Engineering Handbook. New Delhi, Engineers' publisher, pp. 2-37.

[17] Musharraf, A., Hossain, M. S. and Islam, M. F., 2011. Potential of locally available clay as raw material for traditional-ceramic manufacturing industries. Journal of Chemical Engineering, 26, pp. 34-37.

[18] Nyakairu, G. W. and Koeberl, C., 2001. Mineralogical and chemical composition and distribution of rare earth elements in clay-rich sediments from central Uganda. Geochemical Journal, 35 (1), pp. 13-28. 